$\overline{\text { Editorial }}$

\title{
Materials Research - Ibero-american Journal of Materials
}

This issue contains a selection of papers presented at Fifth Latin American Conference on Metastable and Nanostructured Materials (NANOMAT 2012) which was held in São Carlos, SP, Brazil, during September $30^{\text {th }}$ to October $2^{\text {nd }} 2012$, organized by the Department of Materials Engineering, Federal University of São Carlos, by the Graduate Program in Materials Science and Engineering (PPG-CEM), Federal University of São Carlos and by the State University of Campinas, School of Applied Sciences (Limeira). The triennial series of NANOMAT conferences started in São Pedro - São Paulo - Brazil (2001) and then was followed by Foz do Iguaçu - Paraná - Brazil (2003), Rio de Janeiro - Rio de Janeiro - Brazil (2006) and Mexico City - Federal District - México (2009).

The NANOMAT series are directed to researchers working with all classes of metastable and nanostructured materials (ceramics and glasses, metals and alloys, polymers and composites). Research in these areas has been strongly stimulated in recent years by the developments of new materials with unique mechanical, chemical and physical properties. In this context NANOMAT 2012 provided a comprehensive overview of the fundamental aspects, synthesis, materials, properties and applications in this evolving field of materials science. The sessions of NANOMAT 2012 covered the following themes: Synthesis \& Processing: Phase transformations; Structural characterization; Rapid solidification; Theoretical modeling; Computer simulation; Spray forming; Mechanical alloying; Materials: Bulk metallic glasses; Polymers and nanocomposites; New oxide/ceramic glasses; Rapidly quenched materials; Quasicrystals; Complex metallic alloys; Thin films and Coatings; Nanostructured materials and Properties and Applications: Magnetic properties; Electronic properties; Mechanical properties; Chemical properties; Catalytic properties; Hydrogen in metastable alloys; Physical properties; Health issues; Applications.

During NANOMAT 2012 a total of 208 abstracts were scheduled for presentation submitted by scientists from 17 different countries. From those, 41 contributions were presented in oral sessions, including 31 invited talks and 167 were presented as posters.

The 22 papers that appear in this special issue were reviewed as regular journal papers following the standards of Mat Res, with at least two referee's report before final decision. A total of 45 papers were submitted and only 22 were accepted after this refereeing procedure.

We expect that this special issue can provide the readers a synthesis of the recent developments associated with the field of metastable and nanostructured materials.

We acknowledge the support from Federal University of Sao Carlos and State University of Campinas, and the Brazilian financing agencies FAPESP and CAPES. We are also grateful for the industrial support from Altmann, FEI, Equitecs, Netzsch, EDG, Editora Cubo and EMBRAER. After NANOMAT 2012, the International Advisory Committee suggested to convene for the next conference either in Argentina or in México, in 2015. We wish the organizers of NANOMAT 2015 great success and look forward to meeting you in the next conference.

\author{
Alberto Moreira Jorge Jr. \\ Daniel Rodrigo Leiva \\ Guest Editors
}

